\title{
Pelagic fish assemblages assessed using mid-water baited video: standardising fish counts using bait plume size
}

\author{
Elizabeth C. Heagney ${ }^{1, *}$, Tim P. Lynch ${ }^{2}$, Russ C. Babcock ${ }^{3}$, Iain M. Suthers ${ }^{1}$ \\ ${ }^{1}$ School of Biological Earth and Environmental Science, University of New South Wales, Sydney, New South Wales 2052, \\ Australia \\ ${ }^{2}$ Jervis Bay Marine Park, PO Box 89, Huskisson, New South Wales 2540, Australia \\ ${ }^{3}$ CSIRO Marine Research and Atmospheric Research, Private Bag No 5, Wembley, Western Australia 6913, Australia
}

\begin{abstract}
We used a novel mid-water baited remote underwater video (BRUV) technique to survey pelagic and mid-water fish assemblages at Lord Howe Island Marine Park, off eastern Australia $\left(31.5^{\circ} \mathrm{S}, 159.1^{\circ} \mathrm{E}\right)$. We found differences in assemblages among regions separated on a scale of $\sim 10 \mathrm{~s}$ of kilometres. Of the environmental variables measured in the present study (depth, temperature, water current speed), current speed had the greatest influence on the structure of pelagic assemblages. Carcharhinus galapagensis, Seriola rivoliana and Scomber australasicus had similar distributions and were associated with low flow environments. Seriola lalandi was associated with the higher flow environments sampled during our surveys, although current speeds in the sample area were relatively slow ( 0.03 to $0.34 \mathrm{~m} \mathrm{~s}^{-1}$; mean $0.17 \mathrm{~m} \mathrm{~s}^{-1}$ ). Relationships between pelagic assemblages and current speed were detected when abundances were calculated using an area-based approximation for plume dispersal, but were not detected using a linear approximation, or when current was assumed constant across all BRUV deployments. Our results demonstrate the difficulty in separating the dual effects of current speed in BRUV studies: the effect of current on bait plume size and associated estimates of fish abundance, and the role of current as an aspect of preferred pelagic fish habitat. We recommend the use of area-based approximations of plume dispersal and the inclusion of accurate estimates of current speed as a statistical covariate when interpreting mid-water BRUV data. Our results indicate that oceanographic characteristics can be important for pelagic fish habitat selection over the scale of kilometres and should be considered during marine protected area zoning.
\end{abstract}

KEY WORDS: Marine protected area (MPA) - No-take sanctuary zone $\cdot$ Shark · Galapagos whaler · Oceanography $\cdot$ Carangidae $\cdot$ Carcharhinidae $\cdot$ Lord Howe Island

Resale or republication not permitted without written consent of the publishe

\section{INTRODUCTION}

Pelagic fish are often overlooked during the design and implementation of marine protected areas (MPAs) and during subsequent monitoring programs. However, increases in the biomass of carangids and other large predatory fish have been reported in MPAs in Hawaii and the Philippines (Russ \& Alcala 1996, Williams et al. 2006), suggesting that pelagic fish may benefit from MPA protection. Designing MPAs to maximize protection for pelagic species, and monitoring changes after implementation, requires knowledge of pelagic distributions and habitat preferences. Conservation and monitoring programs based on accurate survey data are becoming increasingly urgent, as many pelagic species have experienced serious stock declines (Cury et al. 2000, Myers \& Worm 2003).

Pelagic fish behaviour presents difficulties for the collection and interpretation of accurate survey data. High spatial and temporal variability in pelagic fish distribution and abundance means that traditional fish survey techniques, when applied to pelagic fish 
assemblages, often yield patchy data, with many zeros and limited statistical power (Edgar \& Barrett 1999, Kingsford 1999). Pelagic fish are also fast swimmers that can avoid survey equipment including nets, boats and SCUBA divers (Freon \& Misund 1999, Misund et al. 1999). As a result of these difficulties, pelagic fish research is often reliant on fisheries data, with attendant sampling biases (Gillanders et al. 2001). Fisheries data are also inappropriate for studies in MPAs, where fishing is often banned.

Baited remote underwater video (BRUV) has successfully been used to survey fish assemblages in a number of ecosystems, including shallow coastal reefs (Ellis \& DeMartini 1995, Babcock et al. 1999), continental slopes (Collins et al. 1999a, Speare et al. 2004) and deep abyssal plains (Wilson \& Smith 1984, Priede \& Merrett 1998). BRUV also shows potential to overcome difficulties associated with surveying open-water ecosystems, as pelagic fish have been observed during benthic BRUV surveys (Jones et al. 2003, Cappo et al. 2004, Watson et al. 2005). The use of bait to attract fish to survey gear overcomes problems associated with gear avoidance, as most pelagic fish are opportunistic predator/scavengers that respond to bait plumes (Bozzano \& Sardà 2002, Jones et al. 2003). Using a remote video system also eliminates problems of fish avoiding or being attracted to the research vessel. BRUV has the additional advantage of supplying behavioural data, and insights into inter- or intra-specific interactions (Bozzano \& Sardà 2002, Jones et al. 2003, Collins et al. 2005, Kemp et al. 2006), that may boost our understanding of the structure and function of pelagic ecosystems.

Applying BRUV to mid-water environments requires reconsideration of some of the assumptions in BRUV studies. For example, many BRUV studies assume that each deployment samples an equivalent area by either ignoring water current speed, or by using the average current speed from all deployments to estimate the area sampled by each BRUV (e.g. Hill \& Wassenberg 1999, Henriques et al. 2002, Jones et al. 2003). This may be a reasonable assumption when baits are deployed into the bottom layer where currents are damped by frictional forces, but when baits are deployed into mid-water environments or the surface mixed layer, variable current speeds and turbulent mixing will cause relatively large differences in the area sampled by the bait plume in each BRUV deployment. In such environments it may be more realistic to use in situ measurements of current speed for each BRUV deployment and to include horizontal and/or vertical mixing terms when estimating bait plume area or volume (Sainte-Marie \& Hargrave 1987).

We investigate how different assumptions about bait plume dispersal affect estimates of pelagic fish abun- dance and, particularly, how variations in current speed can influence regional comparisons, assessments of habitat preferences and MPA monitoring. We present findings from mid-water BRUV sampling on the continental shelf around Lord Howe Island, a remote island in the central Tasman Sea, east of Australia. The waters surrounding this small volcanic island provide a rare opportunity to investigate the ecology and behaviour of pelagic fish assemblages, because large-scale commercial fishing efforts targeting pelagic species have always been absent from the region (NSW MPA 2000, NSW DPI 2004). Of particular interest is the regional abundance of tropical sharks, many species of which have been subject to severe over-fishing throughout their range (Ovetz 2006).

\section{MATERIALS AND METHODS}

Study site. Lord Howe Island is an isolated volcanic island approximately $630 \mathrm{~km}$ east of Australia $\left(31.5^{\circ} \mathrm{S}\right.$, $159.1^{\circ} \mathrm{E} ;$ Fig. 1). The island is surrounded by continen-

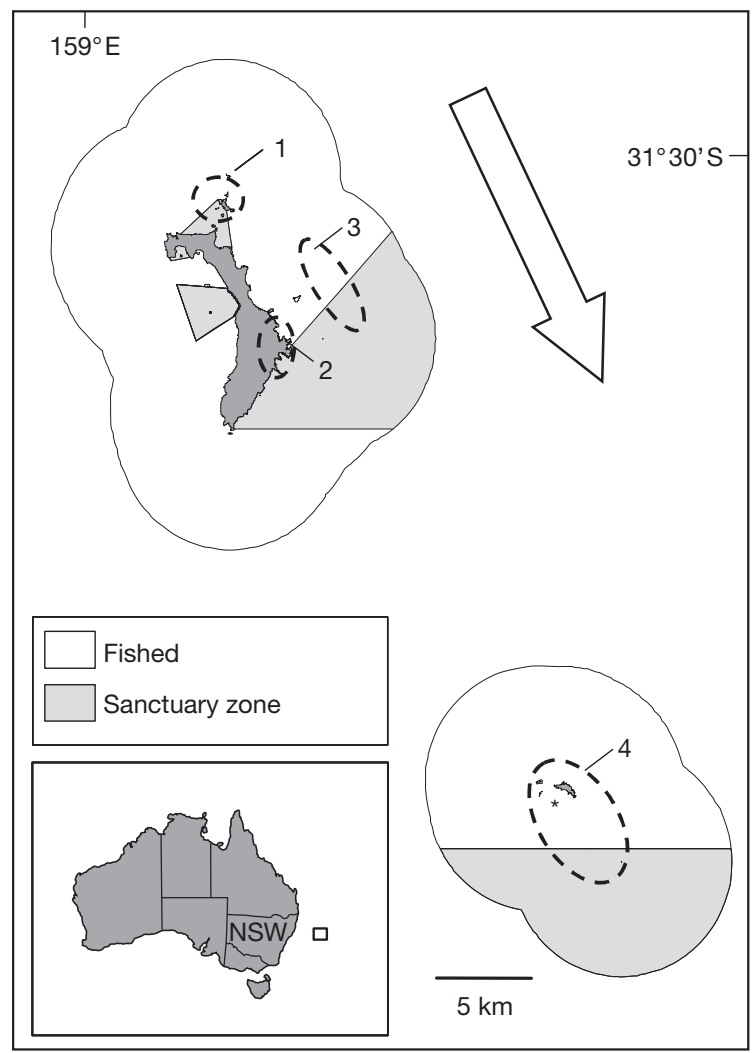

Fig. 1. Chart of Lord Howe Island and Balls Pyramid showing marine park zoning and sampling regions: 1: Admiralty Islands; 2: Red Point/Clear Place; 3: Wolf Rock shoals/the Triangle; 4: Balls Pyramid/South East Rock. Asterisk in Region 4 indicates the location of a small sanctuary zone not visible at the scale of the map provided. Arrow indicates the direction of prevailing current during the survey period 
tal shelf, approximately $10 \mathrm{~km}$ wide, with maximum depth $100 \mathrm{~m}$. Balls Pyramid, a second, smaller island with similar continental shelf structure, is located approximately $25 \mathrm{~km}$ south-east of the main island (Fig. 1). Lord Howe Island is surrounded by the cool waters of the Tasman Sea and is seasonally encircled by the warm East Australian Current (EAC) (Boland \& Church 1981). Water temperatures at the time of sampling (22.2 to $23.2^{\circ} \mathrm{C}$ ) and satellite data (BLUElink www.cmar.csiro.au/bluelink) indicate that EAC waters dominated throughout our study period, and prevailing currents were from the NNW. The waters extending 3 nautical miles around Lord Howe Island and Balls Pyramid were declared an MPA in 1999, and a multiple-use zoning plan was implemented in December 2004 (NSW MPA 2004), just 5 mo before our study. Under the plan, $27 \%$ of the waters surrounding Lord Howe, or 12500 ha, became sanctuary zone where all extractive uses are prohibited (Fig. 1).

Sampling design. Mid-water BRUVs were deployed at multiple sites in 4 regions of the continental shelf of Lord Howe Island and Balls Pyramid (Fig. 1): the Admiralty Islands, comprising a group of 6 smaller islands just north of Lord Howe Island proper (Region 1); Red Point/Clear Place, located on the east coast of the main island (Region 2); Wolf Rock shoals/the Triangle, 2 submerged seamounts off the east coast of the island (Region 3); and Balls Pyramid/South East Rock (Region 4). Regions were separated on a scale of $\sim 10$ s of kilometres, and were chosen in consultation with local recreational and charter boat fishers as areas where pelagic fish are (or have historically been) targeted by either boat-based trolling or rock fishing. Sample regions were also chosen to include both MPA sanctuary zones and areas that have remained open to fishing. A total of 50 BRUV deployments were conducted during the period from 26 March to 9 April 2005. We conducted 10 to 20 replicate deployments in each region, with deployments equally divided between fished areas and MPA sanctuary zones in each region. Where replicate deployments were conducted simultaneously within a region, these were separated on a scale of $\sim 1.5$ to $3 \mathrm{~km}$. Based on maximum recorded current speeds of $0.34 \mathrm{~m} \mathrm{~s}^{-1}$ and a deployment period of $45 \mathrm{~min}$, we estimate the maximum linear extent of any bait plume was $\sim 920 \mathrm{~m}$ and conclude that all BRUV deployments represent independent samples (Ellis \& DeMartini 1995, Cappo et al. 2004).

Mid-water BRUV design. Each BRUV contained a Sony mini-dv camera (TRV 19E and HC 30E series) fitted with a wide-angle lens with a conversion factor of 0.6 (Fig. 2). Cameras were mounted inside custombuilt PVC pipe housings, which were attached to a light aluminium frame, with a horizontal aspect to

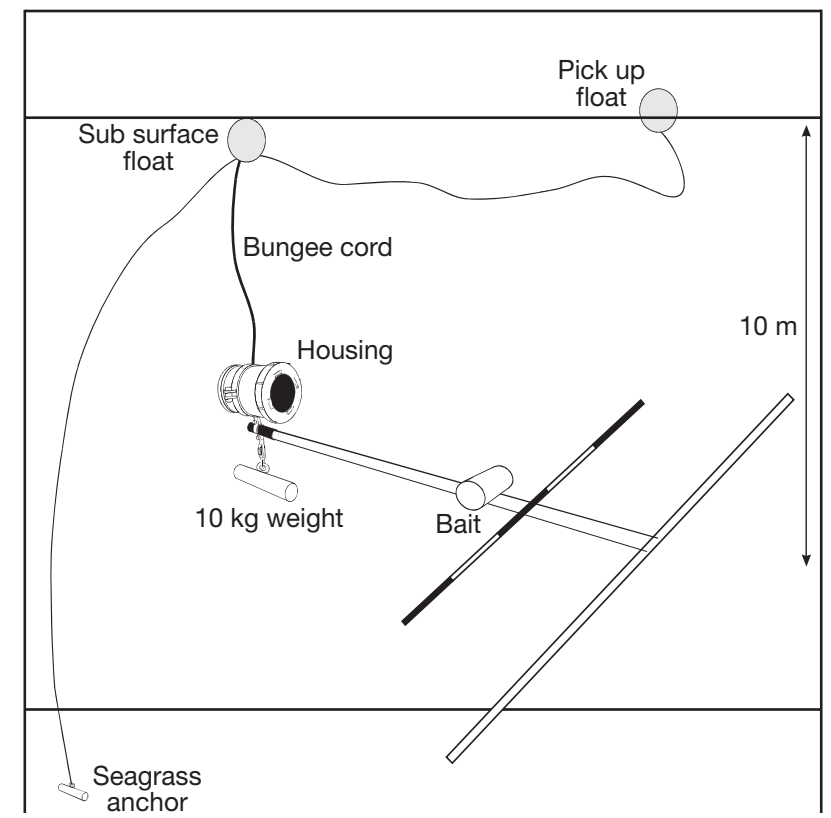

Fig. 2. Schematic diagram of mid-water baited video equipment showing camera housing with horizontal aspect to bait suspended at $10 \mathrm{~m}$ from the surface

a small plastic bait container $(13 \mathrm{~cm}$ length $\times 8 \mathrm{~cm}$ diameter) $1 \mathrm{~m}$ from the lens. PVC tubes $(15 \mathrm{~mm}$ diameter) were attached to the frame at set intervals behind the bait container $(0.5$ and $1 \mathrm{~m})$ as reference markers for fish size and distance from the camera. BRUV frames were designed to align in the current such that the cameras were always pointing downstream, allowing fish to be observed swimming upcurrent into the bait plume. Frames were also designed so that all supports and reference markers were visible in front of the camera to ensure that any fish associating with these structures were visible in camera footage (Jamieson et al. 2006). Each BRUV was attached to a mooring, consisting of an anchor line, anchor, sub-surface buoy and surface buoy (Fig. 2). Video equipment was suspended at a depth of $10 \mathrm{~m}$ from the surface using elasticized bungee cord in order to reduce movement in response to wave action. Video equipment was baited using $100 \mathrm{~g}( \pm 1 \mathrm{~g})$ of a mixture of minced pilchards, bread and tuna oil (8:1:1), all bait components that are commonly used by pelagic fishers in eastern Australia. The mixture was combined in a matrix of vegetable meal (falafel) to ensure that bait release was continual over the deployment period and proportionate to local current speed. Mid-water BRUVs were deployed for $45 \mathrm{~min}$. The research vessel moved well away from the sample sites to avoid confounding effects of fish associating with the vessel. 
At each site we recorded depth, water temperature and current speed. Surface temperature was measured using temperature sensors mounted on the boat hull, and temperature at $10 \mathrm{~m}$ depth was measured using loggers attached to BRUV frames. These were compared to ensure all BRUVs were deployed into the surface mixed layer. Current speed was estimated upon collection of each BRUV using a drogue deployed to $10 \mathrm{~m}$ depth. As the surface buoy had drifted to the extent of its anchor line at the end of each BRUV deployment, it was considered a stationary point. The drogue was deployed next to the stationary buoy and attached to it via a $10 \mathrm{~m}$ line. We estimated current speed from the time taken for the drogue to travel to the extent of the $10 \mathrm{~m}$ line.

Image analysis. Pelagic and mid-water fish observed on video footage were identified to species. For each deployment we recorded $\operatorname{Max} N$, the maximum number of fish from each species seen in a single frame in the first $45 \mathrm{~min}$ of video footage (after Willis et al. 2000). $\operatorname{Max} N$ is a conservative estimate of the total number of fish present in the deployment area, because only a proportion of the fish that detect the bait plume will respond by moving up-current to the video equipment (Løkkeborg 1998), and because fish do not remain at the bait once they have been attracted; rather, they leave the field of view and re-visit the bait on a number of occasions (Kallayil et al. 2003). However, MaxN was considered preferable to time-based measures like time to arrival of first fish or fish arrival rates (Sainte-Marie \& Hargrave 1987, Bailey \& Priede 2002), because these could be confounded by the patchy spatial distribution of pelagic fish schools, interactions between school size and foraging and swimming efficiency (Misund \& Aglen 1992, Day et al. 2001), and potential association between target species and the research vessel (Dagorn et al. 2001, Meekan \& Cappo 2004).
Visibility during our survey period was consistently good $(>30 \mathrm{~m})$, so all fish observed in video footage were included in $\operatorname{Max} N$. Rough size estimates were possible for Carcharhinus galapagensis individuals that swam close and parallel to reference markers (Meekan \& Cappo 2004, Kemp et al. 2006).

Estimating fish abundance. To investigate whether equations used in deep-sea baited camera studies for converting video indices to abundance estimates are applicable to mid-water BRUV data, we compared MaxN/Plume with MaxN/Attract. MaxN/Plume calculates the abundance relative to the size of the bait plume at the completion of a $45 \mathrm{~min}$ deployment, while MaxN/Attract calculates the abundance relative to the size of the bait plume at the latest time a fish could detect the plume and swim to the bait in time to be viewed in the first $45 \mathrm{~min}$ of video footage (SainteMarie \& Hargrave 1987, Priede \& Merrett 1996). We ${\text { compare } \text { MaxN/Plume }_{\text {dist }} \text { with MaxN/Attract }}_{\text {dist }}$ for a linear approximation of bait plume dispersal where:

$$
\text { Plume }_{\text {dist }}=45 \times 60 \times v_{W}
$$

and

$$
\text { Attract }_{\text {dist }}=45 \times 60 /\left[\left(1 / V_{W}\right)+\left(1 / V_{f}\right)\right]
$$

and where $V_{W}$ is current speed and $V_{f}$ is fish swimming speed ( $\mathrm{m} \mathrm{s}^{-1}$; Priede \& Merrett 1996). Comparisons were conducted for 4 pelagic species considered representative of the range of fish sizes and swimming capabilities observed in our study (Table 1). Published estimates of fish size and swimming speeds were used (Henriques et al. 2002). Where these were unavailable, published swimming speed data for a congener with a similar aspect ratio were used (Table 1). All estimates represent the maximum cruising speed reported for each species (Sainte-Marie \& Hargrave 1987).

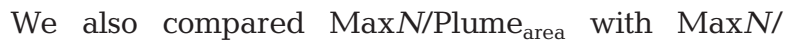
Attract $_{\text {area }}$ for a triangular area approximation of bait plume dispersal (Sainte-Marie \& Hargrave 1987, Hill \&

Table 1. Mean maximum swimming speed estimates $\left(\mathrm{m} \mathrm{s}^{-1}\right)$ for 4 pelagic species estimated from maximum swimming speed in body lengths (BL) per second and mean fish length $(0.5 \times$ maximum length reported in the literature). Where published data for observed species were unavailable, we have used maximum swimming speed of a congener with similar aspect ratio.

\begin{tabular}{|c|c|c|c|c|c|}
\hline Species & Surrogate & $\begin{array}{l}\text { Max. speed } \\
\quad\left(\mathrm{BL} \mathrm{s}^{-1}\right)\end{array}$ & $\begin{array}{l}\text { Mean FL } \\
\quad(\mathrm{m})\end{array}$ & $\begin{array}{l}\text { Max. speed } \\
\quad\left(\mathrm{m} \mathrm{s}^{-1}\right)\end{array}$ & Source \\
\hline Carcharhinus galapagensis & C. leucas & 3.65 & $2.0^{\mathrm{a}}$ & 7.3 & Bainbridge (1958) \\
\hline Seriola lalandi & - & 2.30 & 1.0 & 2.3 & $\begin{array}{l}\text { Kuiter (2000), } \\
\text { Clark \& Seymour (2006) }\end{array}$ \\
\hline Paracaesio xanthurus & Pristopomoides filamentosus & 3.00 & 0.2 & 0.6 & $\begin{array}{l}\text { Kuiter (2000), } \\
\text { Ellis \& DeMartini (1995) }\end{array}$ \\
\hline Scomber australasicus & Sc. japonicus & 4.50 & 0.3 & 1.4 & $\begin{array}{l}\text { Hutchins \& Swainston (1999) } \\
\text { Nauen \& Lauder (2000) }\end{array}$ \\
\hline
\end{tabular}
FL: fork length 
Wassenberg 1999), assuming horizontal turbulent mixing occurred at a rate of one-third the current

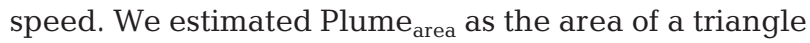

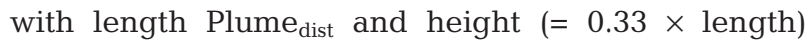
and Attract $_{\text {area }}$ as the area of a triangle with length Attract $_{\text {dist }}$ and width (= $0.33 \times$ length $)$. A scaling variable of a was chosen as a conservative estimate of mixing given that current speeds in the sample area were relatively slow $\left(0.03\right.$ to $0.34 \mathrm{~m} \mathrm{~s}^{-1}$; mean $0.17 \mathrm{~m}$ $\mathrm{s}^{-1}$ ) and that wave action on BRUVS enhanced bait dispersion. Vertical mixing, which is likely to be substantial in the surface mixed layer, has been excluded from our model. Based on our comparisons (see 'Results'), we conducted all further analyses using $\operatorname{MaxN}_{1}{\operatorname{MaxN} / \text { Plume }_{\text {dist }} \text { and MaxN/Plume }}_{\text {area }}$.

Identifying pelagic fish habitat. Pelagic and midwater fish assemblages, comprising the 6 most abundant species attracted to baits, were compared using a 2-factor, full-factorial ANOVA design with the factors Zone (fished versus sanctuary; fixed) and Region (random). Comparisons were conducted using DISTLM (Anderson 2001, McArdle \& Anderson 2001). Data were fourth-root transformed to minimize the influence of highly abundant or schooling species, and Bray-Curtis dissimilarity matrices were used. High sighting rates of Carcharhinus galapagensis enabled similar analyses to be conducted on abundance data for this species; again abundance data were squareroot transformed. DISTLM was used also to perform permutational regression between pelagic assemblages and environmental variables (water current speed, temperature, depth) and to compare environmental variables among sample regions and MPA zones. On the basis of our results, all DISTLM analyses were repeated with current speed as an included covariate. Each of the above analyses was conducted using $\operatorname{Max} N$, MaxN/Plume $_{\text {dist }}$ and MaxN/Plume area in order to investigate how assumptions about bait plume dispersal affected results. Associations between pelagic species were determined using principal components analysis of MaxN/Plume ${ }_{\text {area }}$ abundance data, with varimax rotation.

\section{RESULTS}

\section{Pelagic fish assemblages around Lord Howe Island}

Mid-water BRUV surveys identified 11 pelagic or mid-water species from 5 families: Carangidae, Carcharhinidae, Kyphosidae, Lutjanidae and Scombridae (Table 2). Of these, 7 species were abundant and observed on multiple occasions at a variety of sample sites, while the remaining 4 were observed only once. Several pelagic or mid-water species, including Seriola lalandi, Pseudocaranx dentex, Kyphosus sydneyanus and Paracaesio xanthurus, were often observed in schools of 10s of individuals. Two different colour forms of $P$. dentex were observed during video surveys: those with grey or white-tipped dorsal fins, which are common along the NSW coast and a second yellow-finned variant (Hutchins \& Swainston 1999). All Kyphosus bigibbus individuals observed were of the lesscommon, all-yellow colour variant described by Myers (1999), and were observed in mixed schools with K. sydneyanus.

The most commonly observed species during BRUV sampling was Carcharhinus galapagensis, which was observed on $80 \%$ of video deployments. A single individual from a second carcharhinid species, Galeocerdo cuvier, was also observed. All C. galapagensis whose lengths were estimated were juveniles, ranging from

Table 2. Pelagic species observed using mid-water BRUV (baited remote underwater video), number of individuals sighted, number of deployments (out of 50) on which sightings were made and maximum school sizes. Individuals from 12 additional 'reef fish' families were also observed: Acanthuridae, Balistidae, Chaetodontidae, Dasyatidae, Fistulariidae, Girellidae, Labridae, Lethrinidae, Microcanthidae, Monocanthidae, Pomacentridae, Serranidae

\begin{tabular}{|c|c|c|c|c|c|}
\hline Family & Species & Common name & $\begin{array}{l}\text { Individuals } \\
\text { (no.) }\end{array}$ & $\begin{array}{l}\text { Sightings } \\
\text { (no.) }\end{array}$ & $\begin{array}{l}\text { Max. } \\
\text { school size }\end{array}$ \\
\hline Carcharhinidae & $\begin{array}{l}\text { Carcharhinus galapagensis } \\
\text { Galeocerdo cuvier }\end{array}$ & $\begin{array}{l}\text { Galapagos whaler } \\
\text { Tiger shark }\end{array}$ & $\begin{array}{c}111 \\
1\end{array}$ & $\begin{array}{c}40 \\
1\end{array}$ & $\begin{array}{l}9 \\
1\end{array}$ \\
\hline Carangidae & $\begin{array}{l}\text { Seriola lalandi } \\
\text { Seriola rivoliana } \\
\text { Pseudocaranx dentex } \\
\text { Caranx sp. }\end{array}$ & $\begin{array}{l}\text { Yellowtail kingfish } \\
\text { Highfin amberjack / almaco jack } \\
\text { White trevally / silver trevally } \\
\text { Trevally sp. }\end{array}$ & $\begin{array}{c}79 \\
10 \\
121 \\
3\end{array}$ & $\begin{array}{l}12 \\
4 \\
8 \\
3\end{array}$ & $\begin{array}{c}34 \\
4 \\
60 \\
1\end{array}$ \\
\hline Kyphosidae & $\begin{array}{l}\text { Kyphosus sydneyanus } \\
\text { Kyphosus bigibbus }\end{array}$ & $\begin{array}{l}\text { Sydney drummer } \\
\text { Grey sea chub }\end{array}$ & $\begin{array}{c}77 \\
1\end{array}$ & $\begin{array}{l}9 \\
1\end{array}$ & $\begin{array}{c}40 \\
1\end{array}$ \\
\hline Lutjanidae & Paracaesio xanthurus & Southern fusilier / painted lady & 988 & 20 & 200 \\
\hline Scombridae & $\begin{array}{l}\text { Scomber australasicus } \\
\text { Acanthocybium solandri }\end{array}$ & $\begin{array}{l}\text { Blue mackerel/slimy mackerel } \\
\text { Wahoo }\end{array}$ & $\begin{array}{c}37 \\
1\end{array}$ & $\begin{array}{l}8 \\
1\end{array}$ & $\begin{array}{c}10 \\
1\end{array}$ \\
\hline
\end{tabular}


$\sim 1.2$ to $\sim 2 \mathrm{~m}$ in length. On 12 occasions we observed behavioural associations between C. galapagensis and other pelagic fish, where fish followed closely behind individual sharks, usually within $1 \mathrm{~m}$, and mirrored shark swimming and turning patterns. Behavioural associations between C. galapagensis and the small pelagic Scomber australasicus were observed on 6 occasions; associations between C. galapagensis and other large pelagic fish (Seriola lalandi, Seriola rivoliana, Pseudocaranx dentex) were also observed on 6 occasions.

\section{Estimating fish abundance}

Most pelagic and mid-water fish were observed arriving at BRUVs from downstream of the bait, indicating that chemosensory cues from the bait plume were a more important attractant than boat noises, structural complexity of BRUV frames, or other cues (Wilson \& Smith 1984, Sainte-Marie \& Hargrave 1987, Collins et al. 1999a). Exceptions were Kyphosus sydneyanus and $K$. bigibbus, which showed no directional patterns in arrival. These species were excluded from further analyses as converting $\operatorname{Max} N$ to abundance based on plume dynamics was considered inappropriate and likely to confound assemblage patterns.
MaxN/Plume $_{\text {dist }}$ and MaxN/Attract dist $_{\text {were highly }}$ correlated for the 4 species examined $\left(\mathrm{R}^{2}>0.99\right)$. Slopes of ${\mathrm{MaxN} / \text { Plume }_{\text {area }} \text { versus MaxN/Attract }}_{\text {area }}$ were close to 1 for fast-swimming species (1.02 for Carcharhinus galapagensis, 1.06 for Seriola lalandi) and were slightly higher for slower swimmers (1.18 for Paracaesio xanthurus, 1.13 for Scomber australasicus). Similar trends were observed for comparisons between MaxN/

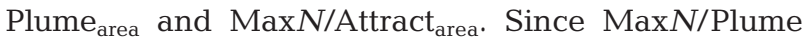
does not incorporate errors associated with estimating fish swimming speed, we used MaxN/Plume (distance or area) for all subsequent analyses.

\section{Identifying pelagic fish habitat}

We detected regional differences in pelagic fish assemblages (Table 3). Highest pelagic fish abundances were observed in Region 1; high abundances of Seriola lalandi and Pseudocaranx dentex in Region 1 related to multiple sighting of relatively large schools (school sizes $\mathrm{n}=30$ and $\mathrm{n}=34$ for $S$. lalandi, $\mathrm{n}=50$ and $\mathrm{n}=60$ for $P$. dentex). Lowest pelagic fish abundances were observed in Region 2, and moderate abundances were observed in Regions 3 and 4 (Fig. 3). Carcharhinus galapagensis, S. lalandi and Paracaesio xanthurus were common to all regions, Scomber australasicus

Table 3. Mean squares, pseudo F-statistic and permutation p-values from DISTLM analyses comparing pelagic fish assemblages and Carcharhinus galapagensis abundance across regions, marine protected area (MPA) zones and environmental variables. +current: current was included as a covariate in analysis. Bold values: $\mathrm{p}<0.05$

\begin{tabular}{|c|c|c|c|c|c|c|c|c|c|}
\hline \multirow[t]{2}{*}{ Source } & \multicolumn{3}{|c|}{$\operatorname{Max} N$} & \multicolumn{3}{|c|}{ MaxN/Plume $_{\text {dist }}$} & \multicolumn{3}{|c|}{ MaxN/Plume $_{\text {area }}$} \\
\hline & MS & pseudo- $F$ & $\mathrm{p}($ perm) & MS & pseudo- $F$ & $\mathrm{p}($ perm $)$ & MS & pseudo- $F$ & $\mathrm{p}($ perm $)$ \\
\hline \multicolumn{10}{|l|}{ Pelagic assemblages } \\
\hline Region & 5191 & 2.37 & 0.01 & 5092 & 2.27 & 0.01 & 5000 & 2.13 & 0.01 \\
\hline Region (+current) & 5508 & 2.63 & 0.006 & 5424 & 2.57 & 0.006 & 5331 & 2.49 & 0.005 \\
\hline Zone & 2229 & 0.82 & 0.24 & 2016 & 0.77 & 0.25 & 2347 & 0.82 & 0.22 \\
\hline Zone (+current) & 4334 & 1.56 & 0.26 & 4094 & 1.47 & 0.27 & 4053 & 1.46 & 0.28 \\
\hline Region $\times$ Zone & 2735 & 1.25 & 0.22 & 2816 & 1.25 & 0.22 & 2858 & 1.22 & 0.23 \\
\hline Region $\times$ Zone (+current) & 2569 & 1.23 & 0.27 & 2560 & 1.21 & 0.27 & 2518 & 1.18 & 0.29 \\
\hline Current & 3670 & 1.59 & 0.20 & 5621 & 2.38 & 0.06 & 9056 & 3.80 & 0.006 \\
\hline Depth & 943 & 0.39 & 0.81 & 1123 & 0.46 & 0.77 & 1153 & 0.53 & 0.73 \\
\hline Temperature & 587 & 0.24 & 0.90 & 657 & 0.27 & 0.89 & 738 & 0.29 & 0.90 \\
\hline \multicolumn{10}{|l|}{ C. galapagensis } \\
\hline Region & 4679 & 2.94 & 0.02 & 4536 & 2.66 & 0.03 & 4381 & 2.25 & 0.05 \\
\hline Region (+current) & 4656 & 3.07 & 0.02 & 4503 & 2.92 & 0.03 & 4330 & 2.67 & 0.03 \\
\hline Zone & 4094 & 3.77 & 0.03 & 3653 & 3.44 & 0.03 & 3514 & 3.18 & 0.03 \\
\hline Zone (+current) & 7456 & 6.27 & 0.06 & 7000 & 6.87 & 0.05 & 6369 & 7.13 & 0.03 \\
\hline Region $\times$ Zone & 1087 & 0.86 & 0.60 & 1057 & 0.62 & 0.65 & 1105 & 0.57 & 0.73 \\
\hline Region $\times$ Zone (+current) & 1385 & 0.91 & 0.46 & 1167 & 0.76 & 0.58 & 1013 & 0.62 & 0.71 \\
\hline Current & 1107 & 0.06 & 0.47 & 4736 & 2.55 & 0.10 & 12304 & 6.46 & 0.005 \\
\hline Depth & 970 & 0.05 & 0.94 & 118 & 0.06 & 0.95 & 206 & 0.95 & 0.94 \\
\hline Temperature & 590 & 0.32 & 0.66 & 603 & 0.31 & 0.68 & 785 & 0.37 & 0.68 \\
\hline
\end{tabular}




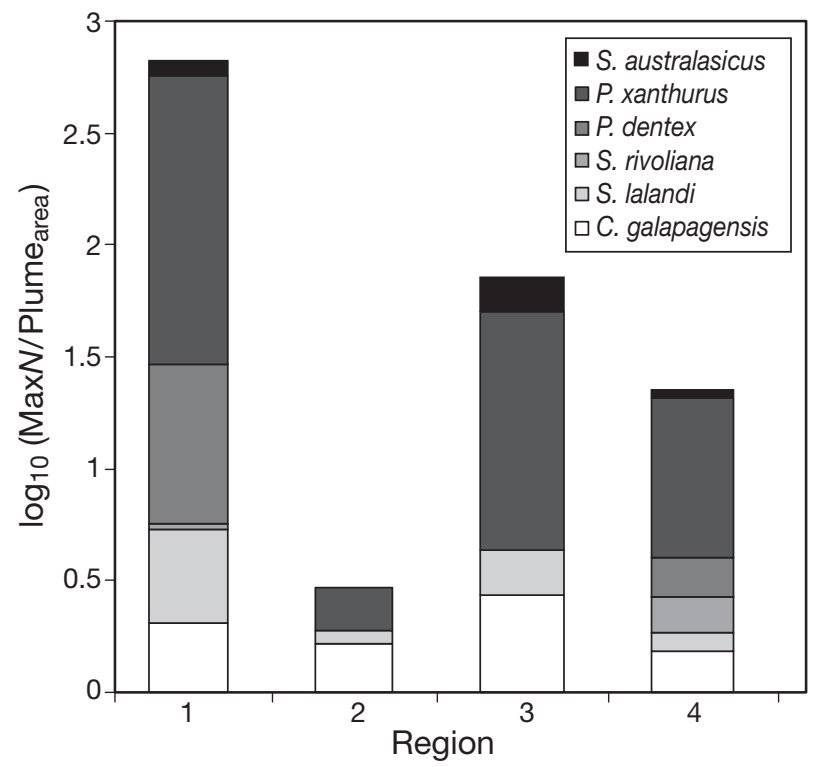

Fig. 3. Mean abundance of 6 pelagic species by sample region. Abundance is based on MaxN/Plume ${ }_{\text {area }}$ and has been $\log _{10}$ transformed. Full taxonomic names, see Table 2

was absent from Region 2, and Seriola rivoliana and $P$. dentex were absent from Regions 2 and 3 (Fig. 3). Similarities were observed for assemblages from Regions 3 and 4, while Regions 1 and 2 each contained distinct assemblages (Fig. 4a). No differences in assemblages were observed between fished areas and MPA sanctuary zones. Of the environmental variables measured, current speed had the greatest influence on pelagic fish assemblages (Table 3). C. galapagensis, Seriola rivoliana and $S$. australasicus were associated with areas of slower current speed, while $S$. lalandi was generally found at sites with faster current speeds (Fig. 4b).

Regional differences in abundance were also observed for Carcharhinus galapagensis (Table 3), which were most abundant in Region 3 and least abundant in Region 4 (Fig. 5a). C. galapagensis abundance was also higher inside MPA sanctuary zones compared with fished areas (Fig. 5b).

\section{Effect of bait plume assumptions}

An inverse correlation between Carcharhinus galapagensis abundance and current speed was detected using MaxN/Plume area (Table 3, Fig. 6). Current speed was also the most important environmental variable structuring pelagic fish populations (Table 3); again significant correlations between assemblage composition and current speed were only detected using MaxN/Plume ${ }_{\text {area }}$ although marginally significant differences were detected using MaxN/Plume dist $_{\text {( }}(\mathrm{p}=$ $0.057)$.
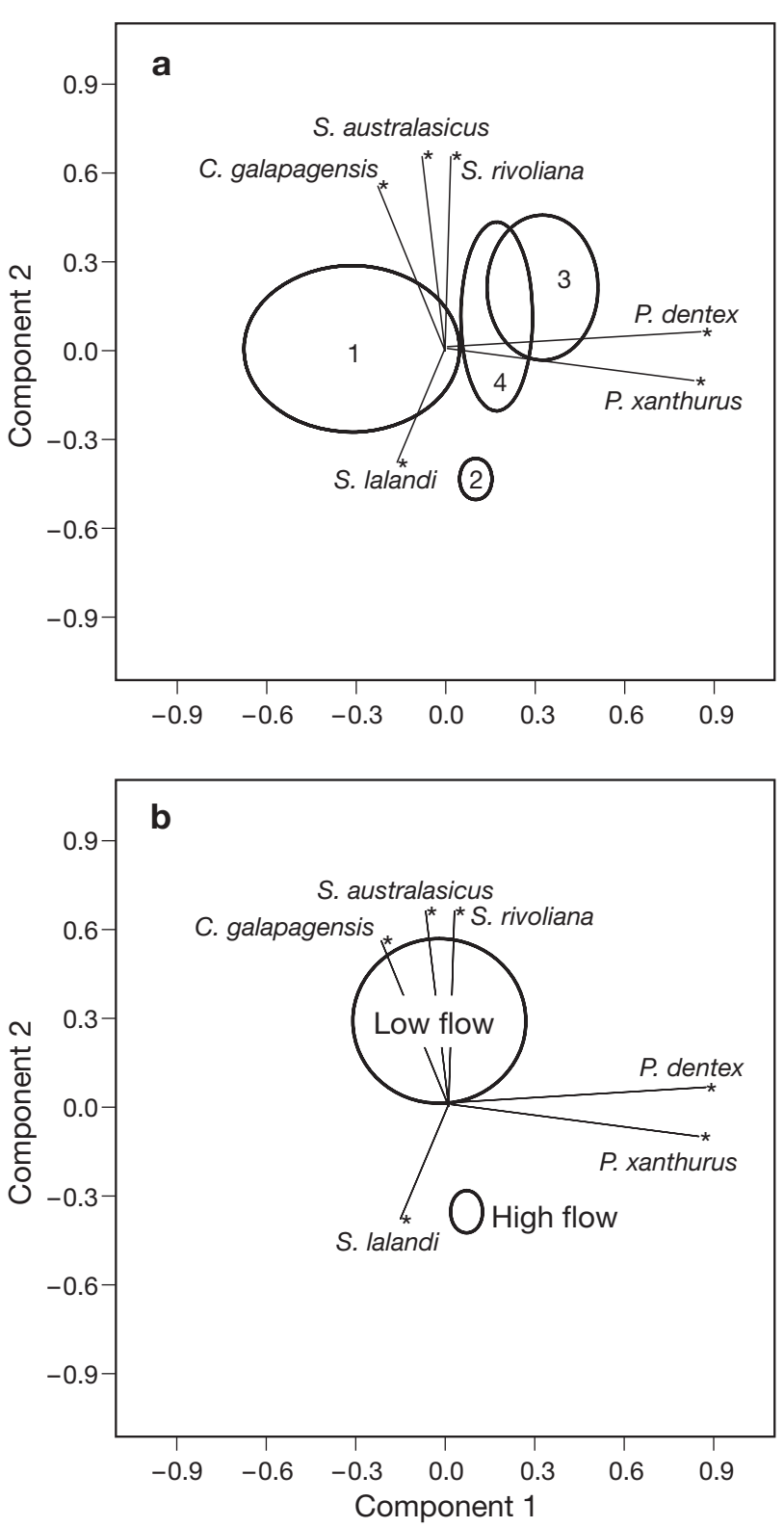

Fig. 4. Component plots showing association between 6 pelagic fish species. Component 1 explains $27 \%$ of variance; Component 2 explains $21 \%$ of variance. Mean component scores ( \pm SE) are overlain for: (a) each sample region and (b) high versus low flow areas. High flow: current speeds $\geq 0.17 \mathrm{~m}$ $\mathrm{s}^{-1}$ (mean current speed); low flow: current speed $<0.17 \mathrm{~m} \mathrm{~s}^{-1}$. Full taxonomic names, see Table 2

Differences in pelagic fish assemblages and Carcharhinus galapagensis abundance among regions and MPA zones were detected irrespective of the abundance index used (MaxN, MaxN/Plume dist, $_{\text {, MaxN/ }}$ Plume $_{\text {areai }}$ Table 3). However, sensitivity to differences changed depending on whether or not current speed was included as a covariate in DISTLM analyses. The inclusion of a current speed covariate made DISTLM 


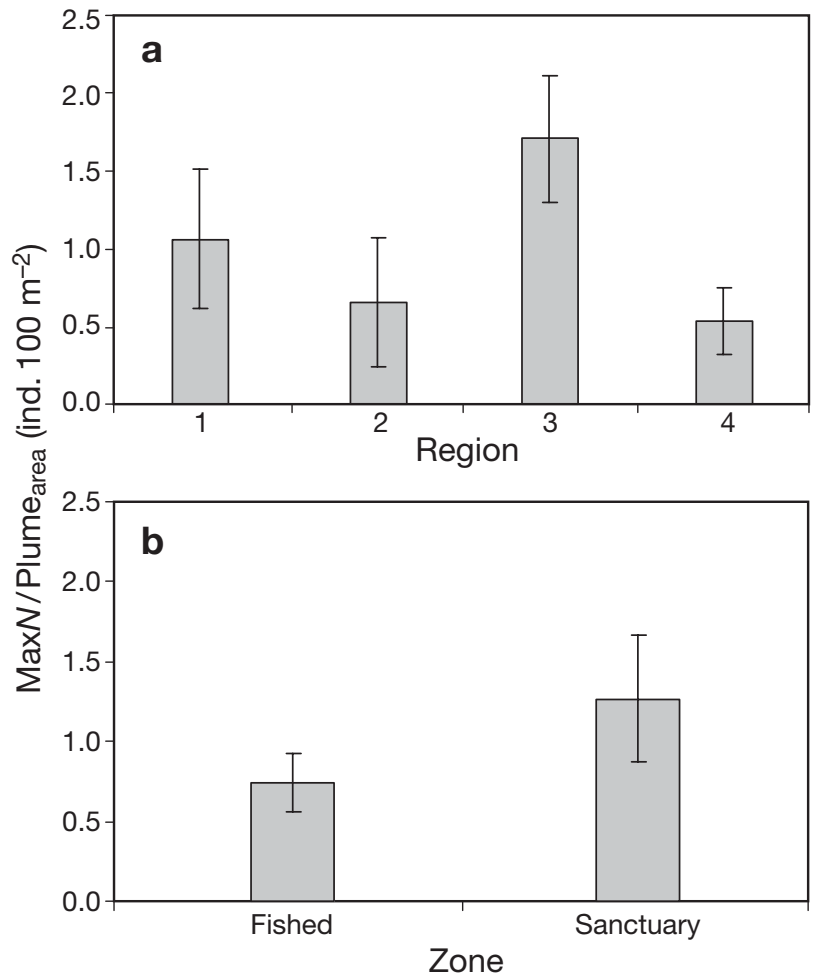

Fig. 5. Carcharhinus galapagensis. Mean abundance: (a) by region and (b) for fished areas versus sanctuary zones. Error bars: $\pm \mathrm{SE}$

more sensitive to differences among regions, but less sensitive to differences between fished areas versus sanctuary zones (Table 3 ). This result was related to systematic differences in current speed observed between fished areas and MPA sanctuary zones (Table 4). Over our 2 wk sampling period, significantly lower mean current speeds were recorded in fished areas compared with MPA sanctuary zones - a trend which was consistent across all 4 regions sampled (Fig. 7). A marginally significant positive correlation was observed between current speed and temperature $(\mathrm{r}=$ $0.06, \mathrm{p}=0.057$ )

Table 4. Results of 3-factor ANOVA comparing current speed across sampled regions, marine protected area zones (fished areas versus sanctuary zones) and interaction terms. Results of ANOVA comparing temperature and depth among treatments were not significant. Bold value: $p<0.05$

\begin{tabular}{|lrccc|}
\hline Source & df & MS & $F$ & $\mathrm{p}$ \\
\hline Region & 3 & 0.012 & 2.418 & 0.244 \\
Zone & 1 & 0.045 & 8.740 & $\mathbf{0 . 0 4 7}$ \\
Region $\times$ Zone & 3 & 0.005 & 0.668 & 0.577 \\
Error & 41 & 0.007 & & \\
Total & 49 & & & \\
\hline
\end{tabular}
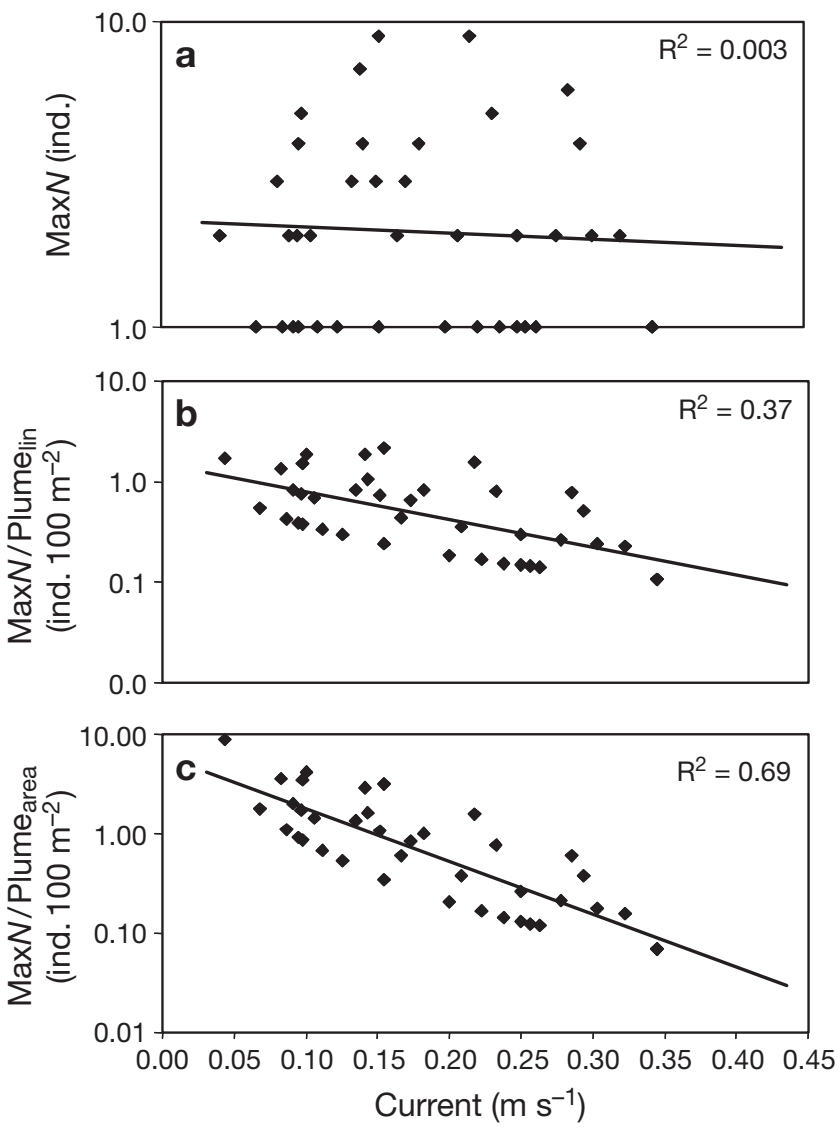

Fig. 6. Carcharhinus galapagensis. Abundance versus current speed as estimated using: (a) MaxN, (b) MaxN/Plume dist $_{\text {and }}$ and (c) MaxN/Plume area (non-zero data only). Note $y$-axis scale shows $\log _{10}$ value

\section{DISCUSSION}

\section{Pelagic and mid-water fish assemblages at Lord Howe Island}

Our novel mid-water BRUV surveys identified 11 pelagic and mid-water species, 7 of which were abundant and observed on numerous occasions in multiple regions. Surveys provided data on pelagic fish that are targeted or caught incidentally by local charter and recreational fishers (Carcharhinus galapagensis, Seriola lalandi, S. rivoliana, Pseudocaranx dentex), as well as un-fished pelagic and mid-water species (Paracaesio xanthurus, Scomber australasicus, Kyphosus sydneyanus, $K$. bigibbus), thereby providing important data on the structure of mid-water ecosystems not available through catch statistics. By far the most common species observed during our surveys was C. galapagensis. Sightings included numerous juveniles, although this may indicate a behavioural bias whereby juvenile sharks approach reference markers more 

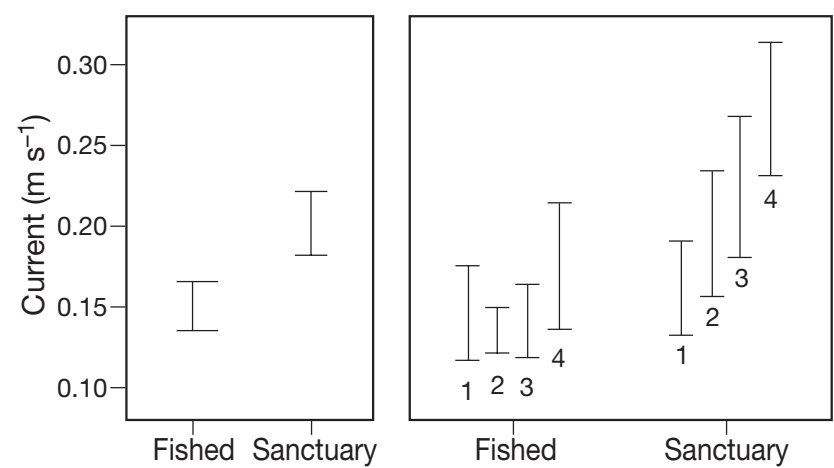

Fig. 7. Mean current speed in fished areas versus sanctuary zones in sample regions, measured over the 2 wk sampling period

often and more closely. The presence of juveniles in the area indicates that the Lord Howe Island continental shelf may be a nursery area for this species, and is consistent with previous studies of C. galapagensis that have found that juveniles are restricted to coastal, or relatively shallow, areas (Last \& Stevens 1994, Wetherbee et al. 1996). BRUV surveys also provided useful qualitative data regarding behavioural associations between C. galapagensis and other pelagic species. Large pelagic species may associate with $C$. galapagensis to enhance camouflage, or due to some feeding advantage conferred by the superior detection and hunting skills of C. galapagensis. As no actual feeding behaviour of associated fish was observed on video footage, it is unclear whether large pelagic species attempt to strike prey detected by C. galapagensis before the sharks, or whether they feed on injured individuals, or scavenge scraps from prey items taken by sharks.

Of the environmental variables measured in our study, water current speed had the greatest influence on the structure of pelagic fish assemblages. Carcharhinus galapagensis, Seriola rivoliana and Scomber australasicus were associated with lower flow environments, while Seriola lalandi was associated with higher flow environments, although the range of current speeds recorded during the survey period indicated that the study area was characterized by relatively slow current speeds $\left(0.03\right.$ to $0.34 \mathrm{~m} \mathrm{~s}^{-1}$; mean $0.17 \mathrm{~m} \mathrm{~s}^{-1}$ ). Flow has previously been identified as an important aspect of habitat for fish assemblages on the SE Australian continental shelf (Williams \& Bax 2001), and associations with particular flow conditions have been observed for other marine predators (Johnston 2005). Habitat preferences for particular flow conditions may relate to zooplankton dynamics-zooplankton are known to accumulate in island wakes, in areas of low flow (Suthers et al. 2004, 2006). Neither temperature nor depth influenced pe- lagic assemblages or abundances in our study. This result is contrary to previous studies (Freon \& Misund 1999), but both variables had a very small range in our study $\left(22.2\right.$ to $23.2^{\circ} \mathrm{C}$ temperature; 15 to $55 \mathrm{~m}$ depth).

\section{Estimating fish abundance from mid-water BRUV: accounting for current speed}

Pelagic fish abundance can be best estimated from mid-water BRUV footage using MaxN/Plume (distance or area) rather than using MaxN/Attract (distance or area). The latter technique was developed by SainteMarie \& Hargrave (1987) and Priede \& Merrett (1996) for deep-sea BRUV studies, which generally have long soak times, on the order of days (e.g. Bozzano \& Sardà 2002, Kemp et al. 2006), and which target organisms that are relatively slow moving (e.g. Collins et al. 1999b). In contrast, our mid-water BRUV surveys used a short soak time (45 min) and targeted fast-swimming species. Both these factors reduce the time between a fish's detection of the bait plume and its subsequent appearance on video footage, minimizing the difference between plume size and distance or area of attraction. Our results are consistent with Ellis \& DeMartini (1995), who conclude that deep-sea techniques for estimating abundance from video footage may not be suitable for BRUV studies conducted in shallower ecosystems.

We considered MaxN/Plume to provide more accurate estimates of pelagic fish abundance from midwater BRUV, because MaxN/Attract requires additional data about fish swimming speeds, which is difficult to obtain (Lowe \& Goldman 2001) and incorporates numerous, often untested, assumptions about fish behaviour around baits. For example, fish swimming speeds around baited gears may not reflect swimming speeds to the bait (Løkkeborg 1998, Kallayil et al. 2003). It is also unclear whether fish swim towards a bait at their natural or 'foraging' or 'cruising' speed, or at their maximum 'burst' speed-indeed the behaviour chosen may vary according to factors such as satiation or the degree of competition for food resources (Moore \& Howarth 1996, Johansson \& Leonardsson 1998). The strong link between fish swimming speed and body size (Plaut 2001, Krause et al. 2005) means that accurate estimates of swimming speed also require accurate estimates of fish size from BRUV footage, which are only possible through the use of stereo video (Harvey et al. 2003). The link between swimming speed and fish size is of particular concern where size varies systematically across treatments, e.g. among sample regions (e.g. Collins et al. 2005) or seasons (e.g. Smith et al. 1997). 
Assumptions about bait dispersal proved important for the interpretation our results. Using different plume models (MaxN versus MaxN/Plume dist $_{\text {versus }}$ MaxN/Plume $_{\text {area }}$ ) affected the outcome of regression analyses comparing fish assemblages and abundances with local current speeds. Significant correlations between pelagic fish assemblages and current speed and between Carcharhinus galapagensis abundance and current speed were only observed using MaxN/ Plume $_{\text {area. }}$ These different outcomes stem from the strength of the derived relationship between abundance indices and current speed. Plume dist $_{\text {increases }}$ linearly with current speed, while Plume area increases as a power function. These different outcomes demonstrate the difficulty in separating the dual effects of current speed in BRUV studies: the effect of current speed on bait dispersal and abundance estimates and the effect of current speed on fish abundance related to habitat preferences for particular flow conditions or correlated environmental variables (e.g. depth, temperature). These can only be resolved through more accurate current speed measurements and bait dispersion models. Modelling plume dynamics is a complex task, which would require separate dispersion models for each component of a bait mixture (e.g. oily components versus larger flesh or bread particles). In the absence of such models, we recommend that abundance be calculated from mid-water BRUV using an area-based estimate of plume dispersal, as this is a conservative estimate that is unlikely to generate falsely derived relationships. For studies with long soak times, bait plume area may be best approximated using an elliptical, rather than a triangular, area (Priede \& Merrett 1996, Bailey \& Priede 2002).

The importance of selecting an appropriate bait plume model is particularly evident when comparing fish assemblages or abundances across treatments, where current speed varies systematically among treatment groups, as observed for fished areas versus sanctuary zones at Lord Howe Island. Current speeds recorded in sanctuary zones around Lord Howe Island over our survey period were significantly higher than those recorded in fished areas (Fig. 7). Observed differences in flow between sanctuary zones and fished areas are likely to vary temporally with variations in EAC/Tasman Sea circulation patterns (Ridgway \& Dunn 2003). MPA monitoring or other studies could be confounded if both regional and temporal variations in current speed are not taken into account. Our data on pelagic fish associations with particular flow conditions provides a standardized baseline for MPA monitoring, which allows any change in distribution or abundance following zoning to be assessed relative to the suitability of the surrounding habitat. The inclusion of current speed as a covariate when analyzing BRUV data can also account for these effects to some degree. We suggest that current speed should be measured using a drogue deployed simultaneously with each BRUV and for the duration of the BRUV as a Lagrangian measure of current that accounts for spatial and temporal variations in current speed or direction. Eulerian measures, like current meters and the short drogue deployment length used in this study, fail to account for small-scale spatial variations in current speed (e.g. eddies or gyres, topographically induced variations to flow; Suthers et al. 2004), which are likely to be as important as, or more important than, temporal changes in current speed for BRUV studies with short soak times (Sainte-Marie \& Hargrave 1987, Hill \& Wassenberg 1999, Henriques et al. 2002).

Consideration should be given to other cues that may attract pelagic fish to BRUVs. Sharks, including carcharhinds, can be attracted to low-frequency instrumental sounds, such as those emitted by a video camera, from a distance of up to $400 \mathrm{~m}$ (Myrberg 2001). Pelagic fish could also be attracted to BRUVs by the structure itself (Freon \& Misund 1999) or by associated interruptions to surrounding currents (Popper \& Carlson 1998). Even though we consider chemosensory cues to have been the most important in our study, knowledge of the 'area of attraction' for all relevant cues may enhance the accuracy of abundance estimates (e.g. Bailey \& Priede 2002). Incorporating the 'search area' traversed by an actively foraging pelagic predator (e.g. Sainte-Marie \& Hargrave 1987, Bailey \& Priede 2002) may further enhance the accuracy of abundance estimates.

Our results do not represent a comprehensive comparison of fished areas and sanctuary zones in the Lord Howe Island Marine Park because of the small number of sites surveyed. Rather, they highlight the importance of accounting for current speed when mid-water BRUV is used to estimate fish abundance or to compare assemblages among regions or treatments with different flow conditions. Our results indicate that oceanographic characteristics can be important for pelagic fish habitat selection over the scale of kilometres, and these should therefore be considered during MPA zoning and monitoring. Surveys of the oceanographic characteristics of pelagic fish habitat around Lord Howe Island should be conducted over a longer time period and a broader scale of oceanographic influences (EAC, Tasman Sea) to identify priority areas for further research or conservation efforts for pelagic species.

Acknowledgements. This research was funded by the NSW Marine Parks Authority, with support from the Commonwealth Scientific and Industrial Organisation (CSIRO) and the University of New South Wales. Thanks to P. Bond and 
Smogsy for assistance in the field. Thanks to A. Nute for assistance designing our mid-water BRUV, and E. Kylberg for assistance in processing video footage. Our sincere thanks to 4 anonymous reviewers whose comments have greatly assisted the preparation of this manuscript.

\section{LITERATURE CITED}

Anderson MJ (2001) A new method for non-parametric multivariate analysis of variance. Austral Ecol 26:32-46

Babcock RC, Kelly S, Shears NT, Walker JW, Willis TJ (1999) Changes in community structure in temperate marine reserves. Mar Ecol Prog Ser 189:125-134

Bailey DM, Priede IG (2002) Predicting fish behavior in response to abyssal food falls. Mar Biol 141:831-840

Bainbridge R (1958) The speed of swimming of fish as related to size and to the frequency and amplitude of the tail beat. J Exp Biol 35:109-133

Boland FM, Church JA (1981) The East Australian Current 1978. Deep-Sea Res I 28:973-957

Bozzano A, Sardà F (2002) Fishery discard consumption rate and scavenging activity in the northwestern Mediterranean Sea. ICES J Mar Sci 59:15-28

Cappo M, Speare P, De'ath G (2004) Comparison of baited remote underwater video stations (BRUV) and prawn (shrimp) trawls for assessments of fish biodiversity in intertidal reef areas of the Great Barrier Reef Marine Park. J Exp Mar Biol Ecol 302:123-152

Clark TD, Seymour RS (2006) Cardiorespiratory physiology and swimming energetics of a high-energy demand teleost, the yellowtail kingfish (Seriola lalandi). J Exp Biol 209:3940-3951

Collins MA, Yau C, Nolan CP, Bagley PM, Priede IG (1999a) Behavioural observations on the scavenging fauna of the Patagonian slope. J Mar Biol Assoc UK 79:963-970

Collins MA, Priede IG, Bagley PM (1999b) In situ comparison of activity in two deep-sea scavenging fishes occupying different depth zones. Proc R Soc Lond B Biol Sci 266: 2011-2016

Collins MA, Bailey DM, Ruxton GD, Priede IG (2005) Trends in body size across an environmental gradient: a differential response in scavenging and non-scavenging demersal deep-sea fish. Proc R Soc Lond B Biol Sci 272:2051-2057

Cury P, Bakun A, Crawford RJM, Jarre A, Quiňones RA, Shannon LJ, Verheye HM (2000) Small pelagics in upwelling systems: patterns of interaction and structural changes in 'wasp-waist' ecosystems. ICES J Mar Sci 57: 603-618

Dagorn L, Josse E, Bach P (2001) Association of yellowfin tuna (Thunnus albacares) with tracking vessels during ultrasonic telemetry experiments. Fish Bull (Wash DC) 99: 40-48

Day RL, Macdonald T, Brown C, Laland KN, Reader SM (2001) Interactions between shoal size and conformity in guppy social foraging. Anim Behav 62:917-925

Edgar GJ, Barrett NS (1999) Effects of the declaration of marine reserves on Tasmanian reef fishes, invertebrates and plants. J Exp Mar Biol Ecol 242:107-144

Ellis DE, DeMartini EE (1995) Evaluation of a video camera technique for indexing abundances of juvenile pink snapper, Pristipomoides filamentosus, and other Hawaiian insular shelf fishes. Fish Bull (Wash DC) 93:67-77

Freon P, Misund OA (1999) Dynamics of pelagic fish distribution and behaviour: effects on fisheries and stock enhancement. Fishing News Books, Cambridge, UK

Gillanders BM, Ferrell DJ, Andrews NL (2001) Estimates of movements and life-history parameters of yellowtail kingfish (Seriola lalandi): How useful are data from a cooperative tagging programme? Mar Freshw Res 52: 179-192

Harvey E, Cappo M, Shortis M, Robson S, Buchanan J, Speare $P$ (2003) The accuracy and precision of underwater measurements of length and maximum body depth of southern bluefin tune (Thunnus maccoyii) with a stereovideo camera system. Fish Res 63:315-326

Henriques C, Priede IG, Bagley PM (2002) Baited camera observations of deep-sea demersal fishes of the Northeast Atlantic Ocean at $15-28^{\circ} \mathrm{N}$ off West Africa. Mar Biol 141: 307-314

Hill BJ, Wassenberg TJ (1999) The response of spanner crabs (Ranina ranina) to tangle nets - behaviour of the crabs on the nets, probability of capture and estimated distance of attraction to bait. Fish Res 41:37-46

Hutchins B, Swainston R (1999) Sea fishes of Southern Australia, 2nd edn. Swainston Publishing and Gary Allen, Freemantle

Jamieson AJ, Bailey DM, Wagner HJ, Bagley PM, Priede IG (2006) Behavioural responses to structures on the seafloor by the deep-sea fish Coryphaenoides armatus: implications for the use of baited landers. Deep-Sea Res I 53: $1157-1166$

Johansson F, Leonardsson K (1998) Swimming speeds and activity levels of consumers at various resource and consumer densities under predation risk. Can J Zool 76:76-82

Johnston DW (2005) Fine scale oceanographic features and foraging marine predators: the ecology and conservation of an island wake in the Bay of Fundy, Canada. Diss Abst Int B Sci Eng 65(12)

Jones EG, Tselepides A, Bagley PM, Collins MA, Priede IG (2003) Bathymetric distribution of some benthic and benthopelagic species attracted to baited cameras and traps in the deep eastern Mediterranean. Mar Ecol Prog Ser 251: $75-86$

Kallayil JK, Joergensen T, Engaas A, Fernoe A (2003) Baiting gill nets-How is fish behaviour affected? Fish Res 61: 125-133

Kemp KM, Jamieson AJ, Bagley PM, McGrath H, Bailey DM, Collins MA, Priede IG (2006) Consumption of large bathyal food fall, a six month study in the NE Atlantic. Mar Ecol Prog Ser 310:65-76

Kingsford MJ (1999) Fish attraction devices (FADs) and experimental designs. Sci Mar 63:181-190

Krause J, Ward AJW, Jackson AL, Ruxton GD, James R, Currie S (2005) The influence of differential swimming speeds on composition of multi-species fish shoals. J Fish Biol 67:866-872

Kuiter RH (2000) Coastal fishes of south-eastern Australia. Gary Allen, Sydney

Last PR, Stevens JD (1994) Sharks and rays of Australia. CSIRO, Hobart

Løkkeborg S (1998) Feeding behavior of cod, Gadus morhua: activity rhythm and chemically mediated food search. Anim Behav 56:371-378

Lowe CG, Goldman KJ (2001) Thermal and bioenergetics of elasmobranches: bridging the gap. Environ Biol Fishes 60:251-266

McArdle BH, Anderson MJ (2001) Fitting multivariate models to community data: a comment on distance-based redundancy analysis. Ecology 82:290-297

Meekan M, Cappo M (2004) Non-destructive techniques for rapid assessment of shark abundance in northern Australia. The Australian Institute of Marine Science, Townsville 
Misund OA, Aglen A (1992) Swimming behaviour of fish schools in the North Sea during acoustic surveying and pelagic trawl sampling. ICES J Mar Sci 49:325-334

Misund OA, Luyeye N, Coetzee J, Boyer D (1999) Trawl sampling of small pelagic fish off Angola: effects of avoidance, towing speed, tow duration and time of day. ICES J Mar Sci 56:275-283

Moore PG, Howarth J (1996) Foraging by marine scavengers: effects of relatedness, bait damage and hunger. J Sea Res 36:267-273

Myers RF (1999) Micronesian reef fishes: a comprehensive guide to the coral reef fishes of Micronesia, 3rd revised and expanded edn. Coral Graphics, Barrigada, Guam

Myers RA, Worm B (2003) Rapid worldwide depletion of predatory fish communities. Nature 423:280-283

Myrberg AA Jr (2001) The acoustical biology of elasmobranches. Environ Biol Fishes 60:31-45

Nauen JC, Lauder GV (2000) Locomotion in scombrid fishes: morphology and kinematics of the finlets of the chub mackerel Scomber japonicus. J Exp Biol 203:2247-2259

NSW DPI (New South Wales Department of Primary Industries) (2004) Fisheries management (general) amendment (restricted fisheries) regulation 2004. NSW Government Printers, Sydney, NSW

NSW MPA (New South Wales Marine Parks Authority) (2000) Solitary Islands Marine Park (NSW) Solitary Islands Marine Reserve (Commonwealth) - Planning issues and options paper. NSW Marine Parks Authority, Coffs Harbour, NSW

NSW MPA (New South Wales Marine Parks Authority) (2004) User guide to the Lord Howe Island Marine Park. Paragon Printers, Canberra, ACT

Ovetz R (2006) The bottom line: an investigation of the economic, cultural and social costs of industrial longline fishing in the Pacific and the benefits of sustainable use marine protected areas. Mar Policy 30:809-820

Plaut I (2001) Critical swimming speed: its ecological relevance. Comp Biochem Physiol 131:41-50

Popper AN, Carlson TJ (1998) Application of sound and other stimuli to control fish behavior. Trans Am Fish Soc 127: 673-707

Priede IG, Merrett NR (1996) Estimation of abundance of abyssal demersal fishes; a comparison of data from trawls and baited cameras. J Fish Biol 49(A):207-216

Priede IG, Merrett NR (1998) The relationship between numbers of fish attracted to baited cameras and population density: studies on demersal grenadiers Coryphaenoides (Nematonurus armatus) in the abyssal NE Atlantic Ocean. Fish Res 36:133-137

Editorial responsibility: Howard Browman (Associate Editorin-Chief), Storebø, Norway
Ridgway KR, Dunn JR (2003) Mesoscale structure of the mean East Australian Current System and its relationship with topography. Prog Oceanogr 56:189-222

Russ GR, Alcala AC (1996) Marine reserves: rates and patterns of recovery and decline of large predatory fish. Ecol Appl 6:947-961

Sainte-Marie B, Hargrave BT (1987) Estimation of scavenger abundance and distance of attraction to bait. Mar Biol 94:431-443

Smith A, Priede IG, Bagley PM, Addison SW (1997) Interception and dispersal of artificial food falls by scavenging fishes in the abyssal Northeast Atlantic: early season observations prior to annual deposition of phytodetritus. Mar Biol 128:329-336

Speare P, Cappo M, Rees M, Brownlie J, Oxley W (2004) Deeper water fish and benthic surveys in the Lord Howe Island Marine Park (Commonwealth Waters): Feb 2004. Australian Institute of Marine Science, Townsville

Suthers IM, Kelley D, Taggart CT, Middleton JH, Rissik D (2004) Entrainment and advection in an island's tidal wake, as revealed by light attenuance, zooplankton, and ichthyoplankton. Limnol Oceanogr 49:283-296

Suthers IM, Taggart CT, Rissik D, Baird ME (2006) Day and night ichthyoplankton assemblages and the zooplankton biomass size spectrum in a deep ocean island wake. Mar Ecol Prog Ser 322:225-238

Watson DL, Harvey ES, Anderson MJ, Kendrick GA (2005) A comparison of temperate reef fish assemblages recorded by three underwater stereo-video techniques. Mar Biol 148:415-425

Wetherbee BM, Crow GL, Lowe CG (1996) Biology of the Galapagos shark, Carcharhinus galapagensis, in Hawaii. Environ Biol Fishes 45:299-310

Williams A, Bax NJ (2001) Delineating fish-habitat associations for spatially based management: an example from the south-eastern Australian continental shelf. Mar Freshw Res 52:513-536

Williams ID, Walsh WJ, Miyasaka A, Friedlander AM (2006) Effects of rotational closure on coral reef fishes in WaikikiDiamond Head Fishery Management Area, Oahu, Hawaii. Mar Ecol Prog Ser 310:139-149

Willis TJ, Millar RB, Babcock RC (2000) Detection of spatial variability in relative density of fishes: comparison of visual census, angling, and baited underwater video. Mar Ecol Prog Ser 198:249-260

Wilson RR Jr, Smith KL Jr (1984) Effect of near-bottom currents on detection of bait by the abyssal grenadier fishes Coryphaenoides spp., recorded in situ with a video camera on a free vehicle. Mar Biol 84:83-91

Submitted: January 10, 2007; Accepted: October 23, 2007 Proofs received from author(s): November 16, 2007 